\title{
RESOLUBILIDADE DO CUIDADO À SAÚDE DA MULHER IDOSA NA ESTRATÉGIA SAÚDE DA FAMÍLIA, EM FEIRA DE SANTANA - BA.
}

\section{Vanuza Silva Campos ${ }^{1}$; Pricila Oliveira de Araújo ${ }^{2}$}

1. Bolsista PIBIC/FAPESB, Graduando em Enfermagem, Universidade Estadual de Feira de Santana, e-mail: vanuzacampos5@gmail.com

2. Orientador, Departamento de Saúde, Universidade Estadual de Feira de Santana, e-mail: poaraujos@ gmail.com

PALAVRAS-CHAVE: Resolubilidade; Saúde do Idoso; Estratégia Saúde da Família

\section{INTRODUÇÃO}

Nas últimas décadas tem-se destacado o processo de envelhecimento da população brasileira que, por sua vez, é acompanhado também pela feminização da velhice, explicada pela maior expectativa de vida das mulheres. Então, tem-se como desafio não apenas atender às necessidades de uma parcela cada vez mais expressiva de idosos, mas também dedicar atenção diferenciada entre os sexos a fim de atender às peculiaridades da saúde da mulher idosa. Entretanto, mesmo diante desse cenário, a realidade é que a mulher idosa ainda enfrenta muitos desafios para obter um cuidado à saúde com resolubilidade, que corresponde à resposta adequada às suas demandas, constituindo-se resultado da confluência das dimensões: acesso, acolhimento, vínculo e responsabilização (SANTOS; ASSIS, 2006). Diante disso, o estudo justificou-se pela demanda cada vez maior de problemas de saúde vinculados à população idosa e, portanto, pela necessidade de ampliar os conhecimentos sobre as dificuldades existentes para a resolubilidade do atendimento desse grupo populacional na ESF e, foi voltado à mulher idosa por esse gênero compreender características específicas e ainda menos estudadas, bem como por frequentar mais assiduamente as unidades de saúde. Então, reconheceu-se a necessidade de responder a essa problemática: como ocorre a resolubilidade do cuidado à saúde da mulher idosa na Estratégia Saúde da Família, em Feira de Santana - BA? Para tanto, o objetivo do estudo foi compreender como ocorre a resolubilidade do cuidado à saúde da mulher idosa na Estratégia Saúde da Família, em Feira de Santana - BA.

\section{METODOLOGIA}

Estudo de caráter qualitativo, descritivo e exploratório, através do qual se buscou compreender como ocorre a resolubilidade do cuidado à saúde da mulher idosa na Estratégia Saúde da Família, em Feira de Santana - BA. Foi realizado em três Unidades Saúde da Família (USF) do município, sendo elas: USF Novo Horizonte, USF George Américo e USF de São José II. Participaram do estudo mulheres com idade mínima de 60 anos, cadastradas nas USF selecionadas, assim como as enfermeiras atuantes nessas unidades. Os critérios de inclusão foram: mulheres com idade mínima de 60 anos, lúcidas e usuárias regulares da Unidade Saúde da Família, com frequência maior ou igual a três consultas no último ano; e enfermeiras com no mínimo 6 meses de atuação na função. A técnica para coleta de dados empregada foi entrevista semiestruturada, realizada nas USF, e eles foram analisados através da análise de conteúdo de Bardin (2011) a partir da transcrição dessas entrevistas e construção de dois quadros sínteses um para as falas das idosas e outro para as falas das enfermeiras, de acordo com o que se destacou nas entrevistadas. Por fim foram realizadas as interpretações e análises dos 
dados encontrados e, então, construiu-se uma discussão a respeito do objeto do estudo baseado nos principais referenciais teóricos sobre a temática.

\section{RESULTADOS E/OU DISCUSSÃO}

Os resultados obtidos e respectiva discussão foram desenvolvidos a fim de se compreender como se dá a resolubilidade do cuidado à saúde da mulher idosa nas USF sob suas diversas vertentes, considerando o contexto de envelhecimento populacional acompanhado pelo processo de feminização da velhice. Para isso, os aspectos centrais foram divididos nas seguintes categorias: 1) Principais agravos de saúde das mulheres idosas nas USF, 2) "Porque remédio aqui a gente não acha, é difícil achar", 3) Dificuldade no acesso à consulta médica e baixa adesão à consulta da enfermeira, 4) Facilidades relacionadas ao acesso físico ao serviço de saúde, 5) Acolhimento e vínculo como potenciadores do cuidado nas USF e 6) Responsabilização das equipes de saúde da família com as usuárias e a confiabilidade destas no serviço. Para se discutir de que forma tem-se dado a resolubilidade do cuidado à saúde dessas mulheres idosas foi imperativo primeiramente identificar quais são as principais demandas apresentadas por elas nas unidades estudadas. Nessa perspectiva, foram identificados a hipertensão e diabetes como principais agravos de saúde do grupo estudado, alinhando-se a outros estudos nacionais, mas chamando atenção para as dificuldades que esses serviços têm tido em controlar o quadro clínico dessas pacientes. A partir das análises, identificou-se que isso pode estar relacionado à manutenção do modelo biomédico, curativista e médico-centrado e, portanto, às poucas medidas voltadas à atenção integral a essa mulher, que aliariam medidas educativas referentes a mudanças nos hábitos de vida e do auto-cuidado à terapia farmacológica (CARVALHO FILHA et al., 2014). Intimamente relacionado a essas características, foi evidenciada também a falta de acesso às medicações nessas unidades, assim como a dificuldade de acesso à consulta médica, enquanto a demanda pela consulta da enfermeira tem sido baixa. Esses fatores relacionam-se ao ainda forte processo de medicalização da saúde, que molda não só as práticas de saúde por parte dos profissionais, mas principalmente a construção das demandas sociais de saúde dessas idosas (CAMARGO JR, 2010; TESSER, 2010; SILVA; MENANDRO, 2014). Assim, todas as ações não relacionadas diretamente ao uso de medicações são desvalorizadas. Essa baixa adesão à consulta da enfermeira, por sua vez, constitui uma grande fragilidade nessas unidades na perspectiva de resolubilidade e atenção integral, pois essa profissional tem papel preponderante na equipe de saúde por conseguir estabelecer uma relação mais próxima e horizontalizada com o usuário, além de contribuir para a continuidade do cuidado além da perspectiva curativista, constituindo um diferencial na assistência e que necessita ser potencializado (NERY, 2006). Em relação ao acesso físico, foram evidenciadas diferenças significativas entre o acesso da população urbana e a rural. Enquanto na área urbana a USF constitui o serviço de saúde mais próximo a essas mulheres, possibilitando até mesmo o acesso a pé e de forma rápida, na zona rural esse acesso é muito dificultado pelas longas distâncias e também dificuldades relacionadas ao transporte público. Além disso, em ambos os contextos também existem dificuldades relacionadas a condições de saúde de algumas idosas, que dificultam esse deslocamento (TRAVASSOS; VIACAVA, 2007; ASSIS et al., 2010; ALENCAR et al., 2013). O acolhimento e o 
vínculo, também fundamentais para a garantia da resolubilidade do cuidado, ainda não se mostram entendidos em sua completa dimensão, então apesar de nas falas eles serem a princípio classificados como bons, em outros momentos existem relatos que evidenciam que os mesmos ocorrem de forma superficial. Porém, esses dois aspectos possuem as USF como ambientes potencializadores, através do modelo de atenção teoricamente preconizado, então é preciso se avaliar porque não têm sido concretizados e quais são essas dificuldades, buscando assim estratégias. No entanto, apesar das dificuldades encontradas nas variadas formas de acesso e acolhimento/vínculo - que evidenciaram impedir a atenção satisfatória às demandas de saúde das mulheres idosas , os serviços mostraram responsabilização por essas usuárias, tentando solucionar as demandas quando possível ou encaminhá-las a outros níveis de atenção e acompanhar os desdobramentos, mas encontram barreiras relacionadas à falta de cooperação e coresponsabilização de outros serviços, destacando a necessidade de se pensar em estratégias que aumentem a articulação das USF com os outros serviços da rede, o que resultaria em um acompanhamento mais efetivo das necessidades de saúde dessa mulher (ASSIS et al., 2010; QUEIROZ et al., 2010). Assim, os resultados deste estudo mostram que ainda existem muitos desafios para a concretização da resolubilidade do cuidado à saúde da mulher idosa em USF no município estudado, visto que essas mulheres enfrentam problemas e dificuldades em todas as vertentes que se referem à atenção resolutiva: acesso, acolhimento, vínculo e responsabilização. Então, como nenhuma dessas dimensões têm sido completamente viabilizadas nas unidades, as demandas de saúde das usuárias idosas não são efetivamente resolvidas e, portanto, esse cuidado e atenção ofertada não ocorrem como resolubilidade.

\section{CONSIDERAÇÕES FINAIS}

Considerando que o atendimento satisfatório às demandas de saúde - o que constitui a resolubilidade da atenção - vai além do contexto biológico, a realidade estudada mostrou-se distante disso. Isso porque a assistência à saúde da mulher idosa foi caracterizada por dificuldades de acesso físico, a medicamentos e funcional (relacionado, por exemplo, ao acesso à consulta médica), fragilidades no acolhimento e vínculo usuária-profissional, assim como dificuldades para a concretização da responsabilização da equipe com essas idosas, relacionadas principalmente à fragilidade da contra-referência e articulação da rede. Desse modo, e em decorrência desses desafios, as idosas vinculadas às USF não estão obtendo respostas satisfatórias desses serviços às suas demandas de saúde e, portanto, essa atenção não tem ocorrido com resolubilidade. Assim, esse contexto exige discussão e reflexões mais profundas a respeito de cada aspecto evidenciado, permitindo então novas perspectivas que auxiliem a reverter esse quadro.

\section{REFERÊNCIAS}

ALENCAR et al. Assistência farmacêutica na estratégia saúde da família: uma análise sobre o acesso. Rev. Bras. Farm.. 94 (3): 219 - 226, 2013. Disponível em: <http://www.rbfarma.org.br/files/rbf-v94n3-04.pdf>. Acesso em: 04 de agosto de 2018. 
ASSIS, MMA., et al., orgs. Produção do cuidado no Programa Saúde da Família: olhares analisadores em diferentes cenários [online]. Salvador: EDUFBA, 2010. 180 p. ISBN 978-85-232- 0877-6. Disponível em: SciELO Books .

BARDIN, L. Análise de conteúdo. São Paulo: Edições 70, 2011.

CARVALHO FILHA et al., Avaliação do controle de hipertensão e diabetes na Atenção Básica: perspectiva de profissionais e usuários. Saúde Debate | Rio de Janeiro, v. 38, n. Especial, p. 265-278, out 2014. Disponível em: <http://www.scielo.br/pdf/sdeb/v38nspe/0103-1104-sdeb-38-spe-0265.pdf >. Acesso em: 07 de agosto de 2018.

CAMARGO JÚNIOR, K.R. Das Necessidades de Saúde à Demanda Socialmente Construída. In: Pinheiro, R.; Mattos, R.A., organizadores. Construção social da demanda: direito à saúde, trabalho em equipe, participação e espaços públicos. $2^{\mathrm{a}} \mathrm{ed}$. Rio de Janeiro: Cepesc/Uerj: Abrasco; 2010. p. 93-103.

NERY, A.A. Necessidades de Saúde na Estratégia Saúde da Família, no município de Jequié - BA: em busca de uma tradução. 2006. Tese (Doutorado) - Escola de Enfermagem de Ribeirão Preto, Universidade de São Paulo, Ribeirão Preto, 2006.

QUEIROZ, M.V.O. et al. Assistência ao adolescente em um serviço terciário: acesso, acolhimento e satisfação na produção do cuidado. Texto contexto - enferm., Florianópolis , v. 19, n. 2, p. 291-299, Junho 2010. Disponível em: $<$ http://www.scielo.br/scielo.php?script=sci_arttext\&pid=S010407072010000200010\&lng=en\&nrm=iso>. Acesso em 28 Set. 2017.

SANTOS, A. M.; ASSIS, M. M. A. Da fragmentação à integralidade: construindo e (des)construindo a prática de saúde bucal no Programa de Saúde da Família (PSF) de Alagoinhas, BA. Ciência e Saúde Coletiva, Rio de Janeiro, v. 11, n. 1, p.53-61, 2006.

SILVA, S.P.C.; MENANDRO, M.C.S. As representações sociais da saúde e de seus cuidados para homens e mulheres idosos. Saúde soc., São Paulo, v. 23, n. 2, p. 626-640, 2014. Disponível em: <http://www.scielo.br/scielo.php?script=sci_arttext\&pid=S010412902014000200626\&lng=en\&nrm=iso>. Acesso em: 08 de agosto de 2018. http://dx.doi.org/10.1590/S0104-12902014000200022.

TESSER, C.D. (org.). Medicalização Social e Atenção à Saúde no SUS. São Paulo: Editora Hucitec, 2010.

TRAVASSOS, C.; VIACAVA, F. Acesso e uso de serviços de saúde em idosos residentes em áreas rurais, Brasil, 1998 e 2003. Cad. Saúde Pública, Rio de Janeiro, v. 23, n. 10, p. 2490-2502, 2007. Disponível em:

<http://www.scielo.br/scielo.php?script=sci_arttext\&pid=S0102311X2007001000023\&lng=en\&nrm=iso >. Acesso em: 04 de agosto de 2018. http://dx.doi.org/10.1590/S0102-311X2007001000023. 